\title{
Detail glucose fluctuation and variability by continuous glucose monitoring (CGM)
}

\begin{abstract}
Authors and colleagues have continued clinical diabetic research in the light of Continuous Glucose Monitoring (CGM) and $\mathrm{M}$ value. $\mathrm{M}$ value is calculated from the daily profile of blood glucose, and it indicates the total numerical value of two factors, which are average blood glucose and mean amplitude of glycemic excursions (MAGE). The case is 53 years old female with Type 1 diabetes mellitus (T1DM), who was on multiple daily insulin injection (MDI). Using FreeStyle Libre, blood glucose was studied for 14 days. Average blood glucose in a day was $169 \mathrm{mg} / \mathrm{dL}, 163 \mathrm{mg} / \mathrm{dL}, 164 \mathrm{mg} / \mathrm{dL}$ and $166 \mathrm{mg} /$ $\mathrm{dL}$ in day $3,5,9,11$, respectively with almost same level. In contrast, the levels of the M value distributed widely from 12.5 to 98.3 . A discrepancy of $\mathrm{HbAlc}$ was found between estimated value and laboratory data on out clinic, which was $7.4 \%$ and $8.0 \%$, respectively. These results suggest that there would be rather large difference in MAGE even though the average blood glucose was almost the same in the 4 days. Furthermore, this investigation would be beneficial for check the detail blood glucose variability associated with various activities, and for better and stable control of blood glucose in T1DM.
\end{abstract}

Keywords: continuous glucose monitoring, freestyle libre, $\mathrm{M}$ value, mean amplitude of glycemic excursions, multiple daily insulin injection, Japan LCD promotion association
Volume 7 Issue I - 2020

\author{
Hiroshi Bando, ${ }^{1,2}$ Koji Ebe, ${ }^{2,3}$ Tetsuo \\ Muneta, ${ }^{2,4}$ Masahiro Bando, ${ }^{5}$ Yoshikazu Yonei ${ }^{6}$ \\ 'Tokushima University / Medical Research, Japan \\ ${ }_{2}^{2}$ Japan Low Carbohydrate Diet Promotion Association, Japan \\ ${ }^{3}$ Takao Hospital, Japan \\ ${ }^{4}$ Muneta Maternity Clinic, Japan \\ ${ }^{5}$ Department of Gastroenterology and Oncology, Tokushima \\ University Graduate School, Japan \\ ${ }^{6}$ Anti-Aging Medical Research Center, Doshisha University, Japan
}

Correspondence: Hiroshi Bando, MD, PhD, FACP,Tokushima University /Medical Research, Nakashowa I-6I,Tokushima, 7700943, Japan, Tel +8I-90-3I87-2485,

Email pianomed@bronze.ocn.ne.jp

Received: March 13, 2020 | Published: May 04, 2020
Abbreviations: CGM: continuous glucose monitoring; T1DM, type 1 diabetes mellitus; MAGE, mean amplitude of glycemic excursions; MDI, multiple daily insulin injection; MARD, mean absolute relative difference; rtCGM, real time CGM; ROC, glycemic rate of change; $\mathrm{LCD}$, low-carbohydrate diet; $\mathrm{CR}$, calorie restriction; BMI, body mass index; MARD, mean absolute relative difference

\section{Introduction}

Recently, diabetes mellitus has been the crucial medical problems across the world. In Type 1 Diabetes Mellitus (T1DM), hypoglycemic episodes have sometimes occurred, which has to be checked and resolved. Among them, continuous glucose monitoring (CGM) has been introduced and developed for some years, and recent report shows further efficacy concerning detecting and preventing hypoglycemic episodes. ${ }^{1}$ The system of CGM shows a variety of effects and influences. Higher benefit of CGM showed lower diabetes distress, higher self-efficacy and other positive attitudes toward technology. ${ }^{2}$ Similarly, CGM has been also applied to Type 2 diabetes mellitus (T2DM), which seems to be an effective strategy to optimize glucose variability. ${ }^{3}$ In case of low carbohydrate diet (LCD) program, CGM can be helpful for making target of better glycemic control with minimal professional support. ${ }^{3}$ As to the development of CGM, it could clarify the actual glucose variability and improve glycemic control in children and adults with T1DM. ${ }^{4,5}$ There are several beneficial points of real time CGM (rtCGM)in the cases who can wear CGM devices more frequently and can respond to regulate appropriately according to the glucose data provided. ${ }^{5,6}$ Thus, treatment using rtCGM associated with multiple daily insulin injection (MDI) confers similar or greater benefits for glycemic profile. ${ }^{7}$ Especially, CGM has been clinically important for T1DM on multiple daily injections of insulin (MDI). ${ }^{8}$ CGM shows the potential benefits of effective use of glycemic rate of change (ROC) arrows for the giving dose adjustments of insulin. ${ }^{9}$
On the other hand, diabetes has to be treated by adequate glycemic treatment, for which there are some standard guidelines. ${ }^{10}$ For diabetic therapy, nutritional treatment has been the fundamental therapy, and various dietary therapies have been reported so far. ${ }^{11}$ Among them, well-known methods in calorie restriction (CR), and low-carbohydrate diet (LCD), Mediterranean diet and others. For clinical application, LCD has been recently in focus. ${ }^{12}$ Various comparison reports were found between CR and LCD. ${ }^{13}$ Formerly, CR had been standard, but Bernstein and others recently initiated LCD some decades ago. ${ }^{14}$ Successively, Dietary Intervention Randomized Controlled Trial (DIRECT) Group and others reported the efficacy of LCD. ${ }^{15}$ Thus, the nutrition method of LCD has been prevalent in North American and European countries. ${ }^{16}$ On the other hand, authors and co-workers have firstly reported LCD in Japan. ${ }^{17}$ Furthermore; authors have continued various clinical researches concerning LCD for years. We have reported the correlation between daily profile of blood glucose and $\mathrm{M}$ value, and continued clinical research and social movement of LCD through of Japan LCD promotion association (JLCDPA)..$^{18,19}$ Furthermore, we have studied glucose variability in diabetic patients using CGM. ${ }^{20}$ As mentioned above, we have combined our research of CGM and $\mathrm{M}$ value together, and describe a case report in this article.

\section{Case report}

History of present illness: The subject was 53 years old female patient with T1DM. She has been treated on insulin for 9 years. Her diabetic control has been fair or in the moderate level so far. HbAlc levels have been about from $7.3 \%$ to $8.4 \%$ in recent period. Though her control of glucose variability has been rather stable, she sometimes has the experience of hyperglycemic and hypoglycemic episodes. The range of her glucose profile has been rather wider from $58 \mathrm{mg} / \mathrm{dL}$ to $382 \mathrm{mg} / \mathrm{dL}$. As her glucose variability revealed rather unstable situation, further detail analysis of glucose profile seemed to be necessary. Then, she was given to check the precise movement of 
her blood glucose by using FreeStyle Libre. This apparatus has been developed for detail analysis of glucose variability and been prevalent in the medical diabetic practice in Japan.

Current physical status: The consciousness has been in alert without any consciousness problem due to hyperglycemia. Her current physical status has been normal without any abnormality. Her vital signs are unremarkable. She showed normal physical examination without any diabetic neurological complication such as any motor or sensory disorders. Her body mass index (BMI) has been 21.1-21.3 $\mathrm{kg} / \mathrm{m}^{2}$.

Laboratory examination: The patient showed the laboratory examination in the following. The standard biochemical data were: GOT $17 \mathrm{U} / \mathrm{mL}$, GPT $24 \mathrm{U} / \mathrm{mL}$, r-GTP $22 \mathrm{U} / \mathrm{mL}$, BUN $17 \mathrm{mg} / \mathrm{dL}$, Cre $0.7 \mathrm{mg} / \mathrm{dL}$, Uric Acid $6.2 \mathrm{mg} / \mathrm{dL}$, TP $6.9 \mathrm{~g} / \mathrm{dL}$, Alb $4.3 \mathrm{~g} / \mathrm{dL}$, HDL $35 \mathrm{mg} /$ dL, LDL $97 \mathrm{mg} / \mathrm{dL}$, TG $167 \mathrm{mg} / \mathrm{dL}$. Hb $13.4 \mathrm{~g} / \mathrm{dL}, \mathrm{RBC} 4.32 \times 10^{6} / \mu \mathrm{L}$ WBC $6600 / \mu \mathrm{L}$, Plt $27.5 \times 10^{4} / \mu \mathrm{L}$. Data related diabetes were $\mathrm{HbA} 1 \mathrm{c}$ $8.0 \%$, post-prandial glucose $254 \mathrm{mg} / \mathrm{dL}$.

Treatment with insulin: The patient with T1DM has been recently treated with insulin therapy for some period. The insulin administration is using 2 kinds of insulin, which is called as multiple daily insulin injection (MDI). The detail method has been in the following: insulin Glargine (Eli Lilly and Company) is given once a day at night, and Novo rapid (Novo Nordisk) is given three times a day just before the meal. As to two kinds of insulin, the former has been Insulin Glargine by BS injection kit FFP including 300 units $/ \mathrm{mL}$, and the latter has been Insulin Aspart by pre-filled pen including 100 units $/ \mathrm{mL}$. This schedule of the insulin administration per day was that Glargine is given 14 units on 2200h and Aspart is given 24, 22, 21 units on just before $0800 \mathrm{~h}, 1200 \mathrm{~h}, 1800 \mathrm{~h}$.

\section{Methods}

\section{Blood variability}

The patient received the detail investigation of CGM using FreeStyle Libre (Abbott, USA) in July 2019. The daily profiles of blood glucose for continuous 14 days have been studied. She had felt no particular specific signs or symptoms during 14 days, which were related to hypoglycemia, hyperglycemia and others related to diabetes.

\section{Continuous Glucose Monitoring (CGM)}

In the actual medical practice, CGM system has been prevalent as a sensor-based device in the diabetic patients. ${ }^{21}$ Most popular device has been the FreeStyle Libre, which was produced by Abbott Diabetes Care Inc., Alameda, CA, USA..$^{21,22}$ As it showed reliable clinical trials for long years, the evaluation has been simple and useful for detecting the minute movement of blood glucose. Its practice is beneficial for convenient and precise, associated with its small size. ${ }^{22}$

\section{M value}

Authors have investigated the detail relationship between Morbus value ( $\mathrm{M}$ value) and glucose variability in various situations for long years. When it is necessary to clarify the profile of blood glucose, the measurement of blood glucose has been performed 7 times from morning until night. Standard times were 08, 10, 12, 14, 17, 19 and $22 \mathrm{~h}$. According to the given data of blood glucose 7 times a day, blood glucose in average and $\mathrm{M}$ value can be calculated by the calculation equation of the formula on $\mathrm{M}$ value. ${ }^{23,24} \mathrm{M}$ value has been used for the evaluation of the useful biomarker for glucose variability. It can show the combined tendency of two valuable meaning. One is the degree of the average blood glucose during the daytime, and another is the width of the glucose fluctuation, showing the mean amplitude of glycemic excursions (MAGE). ${ }^{23-25}$ The both data obtained can speculate the general glucose variability in a day. Consequently, $M$ value can be expressed for one numerical value. It means two valuable tendencies. They are i) the degree of elevated blood glucose in average, and ii) is the increased swinging of the variability of blood glucose. By applying the mathematic method, we can calculate $M$ value for the equation of the logarithmic transformation.

Regarding the significance of $\mathrm{M}$ value, it can be estimated to be the degree of the glucose deviation from the ideal blood glucose profile in a day. ${ }^{24-26}$ The method for calculating the $M$ value has three steps. The first one reveals the basal equation, that is $\mathrm{M}=\mathrm{M}^{\mathrm{BS}}+\mathrm{M}^{\mathrm{W}}$. $\mathrm{M}$ value means the total value of both $\mathrm{M}^{\mathrm{BS}}$ and also $\mathrm{M}^{\mathrm{W}}$. The second reveals the $\mathrm{M}^{\mathrm{w}}$, which shows (maximum blood glucose-minimum glucose)/20. The last one represents that MBS is the mean of MBSBS. Then, summarizing these into one equation, MBSBS has been the individual M-value for each blood glucose. The ideal level of blood glucose is estimated as $120 \mathrm{mg} / \mathrm{dL}$. Consequently, the equation would be calculated as (absolute value of $[10 \times \log$ (blood glucose level/120)] $)^{3} \cdot{ }^{24-26}$ In general, there is usual evaluation for the glucose variability in the light of elevated $\mathrm{M}$ value. As to the result of $\mathrm{M}$ value, the standard normal range is less than 180 , and the borderline would be 180 and more than 180 and less than 320, and abnormal range is thought to be 320 and more than 320 .

\section{Statistical analysis}

In this study, obtained data were shown using mean and standard deviation (SD). As to the daily profile of blood glucose, the data are expressed by mean and SD. When calculating the $\mathrm{M}$ value, the standard equation for $\mathrm{M}$ value was used. In this case, 7 data of glucose were inserted the equation and $\mathrm{M}$ value was calculated. We have used the computerized standard statistical tool, and also standard textbook of the statistics for supporting the calculation. ${ }^{27}$

\section{Results}

\section{Daily profile of blood glucose}

By FreeStyle Libre, the results of the glucose profile on day 3, day 5, day 9 and day 11 were shown in Figure 1. The average glucose level for 24 hours calculated by FreeStyle Libre was almost the same as $169 \mathrm{mg} / \mathrm{dL}, 163 \mathrm{mg} / \mathrm{dL}, 164 \mathrm{mg} / \mathrm{dL}$ and $166 \mathrm{mg} / \mathrm{dL}$, respectively. However, the pattern of glucose profile in these 4 days was different. Estimated $\mathrm{HbA} 1 \mathrm{c}$ from the blood glucose calculated by FreeStyle Libre was $7.4 \%$ or $57 \mathrm{mmol} / \mathrm{mol}$. On the other hand, HbA1c during the same period measured in the outclinic was $8.0 \%$ or $61 \mathrm{mmol} / \mathrm{mol}$. There is a discrepancy between these data.

\section{Analysis of $M$ value}

In current study, the daily profile of blood glucose for 4 days was picked up for further evaluation (Table 1). Average blood glucose for all day was automatically shown by Freestyle Libre, which was described in (Table 1). On the other hand, average blood glucose from $M$ value was calculated from blood variability at seven points from morning to night. The comparison of the average blood glucose between by Freestyle Libre and by $\mathrm{M}$ value was conducted. The former showed similar data in 4 days, which are around $163-169 \mathrm{mg} / \mathrm{dL}$. However, 
the latter showed rather broad distribution from 150 to $187 \mathrm{mg} / \mathrm{dL}$. Furthermore, $\mathrm{M}$ value also showed rather broad distribution from 12.5 to 98.3 , indicating that larger differences were present in the 4 days. This suggests that there would be a large difference in mean amplitude of glycemic excursions (MAGE) even though the average value is similar.

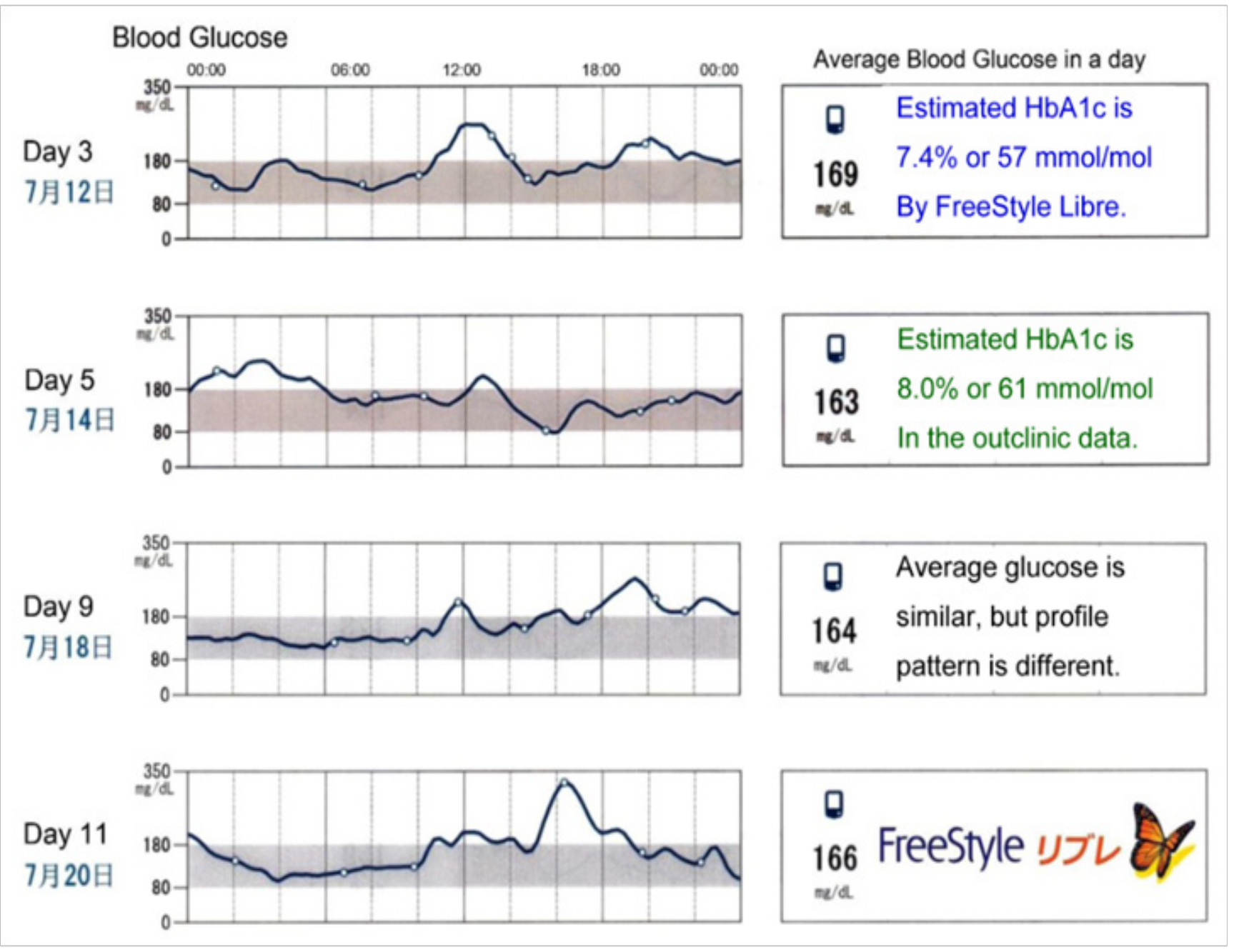

Figure I Results of daily profile of blood glucose by CGM.

Table I Comparison between CGM and M value calculation

\begin{tabular}{lcccc}
\hline & Average glucose & Average glucose & Standard deviation & Results of M value \\
\hline on CGM (mg/dL) & on M value (mg/dL) & on M value (mg/dL) & by calculation \\
\hline Day 3 & 169 & 187 & 49.5 & 90.1 \\
Day 5 & 163 & 150 & 16.7 & 12.5 \\
Day 9 & 164 & 178 & 42.9 & 66.9 \\
Day II & 166 & 186 & 55.3 & 98.3 \\
\hline
\end{tabular}




\section{Discussion}

This report showed the detail evaluation in the light of glucose variability by CGM. Patient has some unstable control associated with irregular schedule of lifestyle, physiologically and psychologically. ${ }^{3}$ Using FreeStyle Libre, daily profile of blood variability was studied for 14 days. The analysis of glucose variability by FreeStyle Libre seemed to be beneficial, because precise fluctuation of glucose was clarified. ${ }^{28}$ There is a description of CGM recommendations in the guideline-2019, which is to make better glycemic control without an increase in hypoglycemia or severe hypoglycemia. ${ }^{29}$ It proposed that benefit would correlate with adherence to ongoing use of the device, associated with the level of evidence as rank A. CGM devices can measure interstitial glucose level and have the advantage of giving precise glucose readings, where there is a new generation of implantable variability. ${ }^{30,31}$ In addition, CGM has developed improvement in glucose variability, reduction of hypoglycemia and cost-effectiveness. ${ }^{32,33}$ Clinical practice guidelines have been recently proposed the criteria for CGM use by the endocrine society. ${ }^{34}$ According to the report of 11 RCTs on CGM for T1DM, CGM can alter $\mathrm{HbA} 1 \mathrm{c}(95 \% \mathrm{CI})$ by $-0.28 \%(-0.47,-0.09)$, and reduce the risk of hypoglycemia, particularly in case of lower HbA1c levels. ${ }^{34}$ As to CGM, beneficial key points include examining frequency, current trends, alarms, therapy optimization and diagnosis. ${ }^{35}$ Furthermore, the guideline of Clinical and Laboratory Standards Institute (CLSI) showed several important points. They include point accuracy, trend accuracy, alarms, the stability of the sensor, calibration, time lag and traceability ${ }^{36}$ It has been known that there is a divergence between the HbAlc value estimated by Libre and the HbAlc measured at the outclinic. In current study, the former was $7.4 \%$ and the latter was $8.0 \%$, which has a difference. This tendency seems to be partly due to the fact that CGM cannot detect occasional spike-like elevation of blood glucose. ${ }^{37}$ Another reason would be that blood glucose is measured in every 15 minutes for FreeStyle Libre, which cannot detect minute changes ${ }^{38}$ Furthermore, lower glucose tends to show in lower range of blood glucose less than $100 \mathrm{mg} / \mathrm{dL}$ on Libre system. Consequently, further evaluation with various research accumulations would be expected in the future.

There are accuracy, safety and user acceptability of the FreeStyle libre System for 89 pediatric patients with T1DM. ${ }^{22}$ On the other hand, mean difference (SD) was reported to be $-43.4(20) \mathrm{mg} / \mathrm{dL}$, using FreeStyle Libre SC-CGM. ${ }^{39}$ In addition, it showed lower values in the lower ranges, and underestimation of the effect of meal on glucose response. ${ }^{37}$ The mean absolute relative difference (MARD) of glucose levels in $(<72,72-180,<181)$ was $20.3 \%, 14.7 \%, 9.6 \%$, respectively. ${ }^{38}$ A characteristic point of the patient may include the daily life which is not working in the office outside, but is a housewife spending in the home. She sometimes has delayed schedule of her own daily lives. Then, this situation may influence the widely distributed levels of MAGE and M value. In this study, the case showed some fluctuation of time in daily activity and meal. Then, the peak of blood glucose was also deviated and hyperglycemia was found in the 4 days. Although the average blood glucose for 24 hours was almost the same in 4 days, there were some differences in $\mathrm{M}$ value for 4 days studied.

In summary, blood glucose variability was investigated by FreeStyle Libre in patients with T1DM. CGM application could clarify the detail glucose variability, which would be effective for improving diabetic control. Investigation of $M$ value showed the wider distributed values, indicating unstable glucose variability such as hyperglycemia. Currently obtained results would be one of the reference data for study of CGM and M value in the future.

\section{Acknowledgment}

Authors would like to express our gratitude for understanding and cooperation to the patient and related staffs concerning this study.

\section{Conflicts of interest}

The authors declare no conflict of interest.

\section{Funding}

None.

\section{References}

1. Carlson A, Kanapka L, Miller K, et al. OR22-2 Exposure to hypoglycemia in older adults with type 1 diabetes: baseline characteristics using continuous glucose monitoring data. $J$ Endocr Soc. 2019;3(Suppl 1).

2. Messer LH, Cook PF, Tanenbaum ML, et al. CGM benefits and burdens: two brief measures of continuous glucose monitoring. J Diabetes $\mathrm{Sci}$ Technol. 2019;13(6):1135-1141.

3. Taylor PJ, Thompson CH, Luscombe-Marsh ND, et al. Efficacy of realtime continuous glucose monitoring to improve effects of a prescriptive lifestyle intervention in type 2 diabetes: a pilot study. Diabetes Ther. 2019;10(2):509-522.

4. New JP, Ajjan R, Pfeiffer AF, et al. Continuous glucose monitoring in people with diabetes: the randomized controlled Glucose Level Awareness in Diabetes Study (GLADIS). Diabet Med. 2015;32(5):609617.

5. Pettus J, Price DA, Edelman SV. How patients with type 1 diabetes translate continuous glucose monitoring data into diabetes management decisions. Endocr Pract. 2015;21(6):613-620.

6. Chamberlain JJ, Dopita D, Gilgen E, et al. Impact of frequent and persistent use of continuous glucose monitoring (CGM) on hypoglycemia fear, frequency of emergency medical treatment, and SMBG frequency after one year. $J$ Diabetes Sci Technol. 2015;10(2):383-388

7. Parkin CG, Graham C, Smolskis J. Continuous glucose monitoring use in type 1 diabetes: longitudinal analysis demonstrates meaningful improvements in HbA1c and reductions in health care utilization. $J$ Diabetes Sci Technol. 2017;11(3):522-528.

8. Maiorino M, Petrizzo M, Bellastella G, et al. Continuous glucose monitoring for patients with type 1 diabetes on multiple daily injections of insulin: pros and cons. Endocrine. 2018;59(1):62-65.

9. Giulio F, Valeria F, Clara B. Comment on "The pros and cons of continuous glucose monitoring for patients with type 1 diabetes on multiple daily injections of insulin". Endocrine. 2018;59(1):230.

10. American Diabetes Association. 9. Pharmacologic approaches to glycemic treatment: standards of medical care in diabetes-2019. Diabetes Care. 2019;42(Suppl1):S90-S102.

11. Schwingshacki L, Chaimani A, Hoffmann G, et al. Impact of different dietary approaches on glycemic control and cardiovascular risk factors in patients with type 2 diabetes: a protocol for a systematic review and network meta-analysis. Syst Rev. 2017;6(1):57.

12. Slomski A. Low-Carb diets help maintain weight loss. JAMA. 2019;321(4):335. 
13. Korsmo-Haugen HK, Brurberg KG, Mann J, et al. Carbohydrate quantity in the dietary management of type 2 diabetes: A systematic review and meta-analysis. Diabetes Obes Metab. 2019;21(1):15-27.

14. Bernstein RK. Dr. Bernstein's Diabetes Solution. Little, Brown and company, New York. 1997.

15. Shai I, Schwarzfuchs D, Henkin Y, et al. Dietary intervention randomized controlled trial (DIRECT) group. Weight loss with a low-carbohydrate, mediterranean, or low-fat diet. $N$ Engl J Med. 2008;359(3):229-241

16. Tay J, Thompson CH, Luscombe-Marsh ND, et al. Effects of an energyrestricted low carbohydrate, high unsaturated fat/low saturated fat diet versus a high-carbohydrate, low-fat diet in type 2 diabetes: A 2-year randomized clinical trial. Diabetes Obes Metab. 2018(4);20:858-871.

17. Ebe K, Ebe Y, Yokota S, et al. Low carbohydrate diet (LCD) treated for three cases as diabetic diet therapy. Kyoto Medical Association Journal. 2004;51:125-129.

18. Bando H, Ebe K, Muneta T, et al. Effect of low carbohydrate diet on type 2 diabetic patients and usefulness of M-value. Diabetes Res Open J. 2017;3(1):9-16.

19. Ebe K, Bando $\mathrm{H}$, Yamamoto $\mathrm{K}$, et al. Daily carbohydrate intake correlates with $\mathrm{HbA1c}$ in low carbohydrate diet (LCD). J Diabetol. 2017;1(1):4-9.

20. Bando H. Clinically beneficial application of flash glucose monitoring (FGM). Biomed J Sci \& Tech Res. 2018;11(3):002095.

21. Abbott Diabetes Care.

22. Edge J, Acerini C, Campbell F, et al. An alternative sensor-based method for glucose monitoring in children and young people with diabetes. Arch Dis Child. 2017;102(6):543-549.

23. Schlichtkrull J, Munck O, Jersild M. The M-value, an index of blood sugar control in diabetics. Acta Med Scand. 1965;177(1):95-102.

24. Service FJ, Molnar GD, Rosevear JW, et al. Mean amplitude of glycemic excursions, a measure of diabetic instability. Diabetes. 1970;19(9):644-655.

25. Molnar GD, Taylor WF, Ho MM. Day-to-day variation of continuously monitored glycaemia: a further measure of diabetic instability. Diabetologia. 1972;8(5):342-348.

26. Moberg E, Kollind M, Lins PE, et al. Estimation of blood-glucose variability in patients with insulin-dependent diabetes mellitus. Scand $J$ Clin Lab Invest. 1993;53(5):507-514.
27. Yanai H. Four step excel statistics, 4th Edition, Seiun-sha Publishing Co.Ltd, Tokyo. 2015

28. Kebede MM, Schuett C, Pschke CR. The role of continuous glucose monitoring, diabetes smartphone applications, and self-care behavior in glycemic control: results of a multi-national online survey. $J$ Clin Med. 2019;8(1):109.

29. American Diabetes Association. 7. Diabetes technology: standards of medical care in diabetes-2019. Diabetes Care. 2019;42(Suppl 1):S71S80.

30. Kropff J, Choudhary P, Neupane S, et al. Accuracy and longevity of an implantable continuous glucose sensor in the PRECISE study: a 180-day, prospective, multicenter, pivotal trial. Diabetes Care. 2017;40(1):63-68

31. Ajjan RA. How can we realize the clinical benefits of continuous glucose monitoring?. Diabetes Technol Ther. 2017;19(S2):S27-S36.

32. Rodbard D. Continuous glucose monitoring: a review of successes, challenges, and opportunities. Diabetes Technol Ther. 2016;18 Suppl 2:S23-S213.

33. Vigersky RA. The benefits, limitations, and cost-effectiveness of advanced technologies in the management of patients with diabetes mellitus. J Diabetes Sci Technol. 2015;9(2):320-330.

34. Peters AL, Ahmann AJ, Battelino T, et al. Diabetes technologycontinuous subcutaneous insulin infusion therapy and continuous glucose monitoring in adults: an endocrine society clinical practice guideline. J Clin Endocrinol Metab. 2016;101(11):3922-3937.

35. Slattery D, Choudhary P. Clinical use of continuous glucose monitoring in adults with type 1 diabetes. Diabetes Technol Ther. 2017;19(S2):S55-S61.

36. Klonoff D, Bernhardt P, Ginsberg GH, et al. A performance metrics for continuous interstitial glucose monitoring; approved guideline. USA. CLSI. 2008;28(33):p1-57.

37. Fokkert MJ, van Dijk PR, Edens MA, et al. Performance of the freestyle libre flash glucose monitoring system in patients with type 1 and 2 diabetes mellitus. BMJ Open Diabetes Res Care. 2017;5(1):e000320.

38. Ólafsdóttir AF, Attvall S, Sandgren U, et al. A clinical trial of the accuracy and treatment experience of the flash glucose monitor freestyle libre in adults with type 1 diabetes. Diabetes Technol Ther. 2017;19(3):164-172.

39. Schierenbeck F, Franco-Cereceda A, Liska J. Accuracy of 2 different continuous glucose monitoring systems in patients undergoing cardiac surgery. J Diabetes Sci Technol. 2017;11(1):108-116. 